\title{
Modeling, Simulation and Identification for Control of Tandem Cold Metal Rolling
}

\author{
Péricles Guedes Alves ${ }^{\mathrm{a} *}$, José Adilson de Castro ${ }^{\mathrm{a}}$, \\ Luciano Pessanha Moreira ${ }^{\text {a }}$ Elder Moreira Hemerly ${ }^{\text {b }}$ \\ ${ }^{a}$ Programa de Pós-graduação em Engenharia Metalúrgica e de Materiais - PPGEMM, \\ Escola de Engenharia Industrial Metalúrgica de Volta Redonda - EEIMVR, \\ Universidade Federal Fluminense - UFF, CEP 27255-125, Volta Redonda, RJ, Brazil \\ ${ }^{\mathrm{b}}$ Instituto Tecnológico de Aeronáutica - ITA, Divisão de Engenharia Eletrônica, \\ CEP 12228-900, São José dos Campos, SP, Brazil
}

Received: December 8, 2011; Revised: June 10, 2012

\begin{abstract}
This paper describes a modeling procedure for tandem cold metal rolling, including the linearization step and system identification for control. The tandem cold rolling process is described by a mathematical model based on algebraic equations developed for control purposes and empirical relations. A state-space model is derived and detailed analyses in open loop are presented, concerning the sensitivity with regard to the variations in process parameters and results for the application of a new subspace identification method are compared with classical methodologies. Therefore, this work intents to be a contribution for developments in new control strategies for tandem cold rolling process that offer the potential to reduce the design efforts, the commissioning time and maintenance in rolling mills. The preliminary results obtained with this model have shown reasonable agreement with operational data presented at literature for industrial cold rolling process.
\end{abstract}

Keywords: rolling mill control, tandem cold rolling, process simulation, mathematical model, system identification

\section{Introduction}

The tandem cold rolling of metal is a highly complex engineering process, with interactions of the multiple process variables, non-linearity and time delays, both extremely dependents of the operating conditions and the rolling mill speed. In general, the rolling mill automation technology deal with the control problem by division into sub problems, where both the adjust thickness and the interstand tension are independent ${ }^{1}$, decentralized strategy. This classical strategy is employed and the results produced are acceptable, but fundamentals studies ${ }^{2,3}$ show the possibility of important progresses in product quality by the use of advanced control strategies.

The process controller design is essentially based on an adequate process model for control. A model for control, differently from a model for prediction is not characterized by great math complexity. The aim is to achieve a model with a good similarity to the process variable in the operating point neighborhood, and that be easily implemented computationally. The dominant idea ${ }^{4-7}$ is the process linearization and the state space modeling practice, usually recommended for MIMO systems, multiple-input multiple-output system.

As well as the modeling and simulation, the identification of the process is an essential step in development of new controllers. In industrial applications, in general, there

are complex plants, petrochemical ${ }^{8}$, iron and steel, etc. In general models for these plants are sought for in the standard black box state space linear form, since the main use for these models is to enable the design of a predictive controller.

The subspace identification method (SIM) is a good candidate for performing identification of industrial plants, since this method is tailored for obtaining MIMO black box linear state space models. SIM's can deal with open or closed loop operation, and in this last case a decorrelation preprocessing of the data is necessary, for avoiding a biased model.

The SIM do not require the use of any initial parameter estimate, and the model structure, namely the number of states, is also obtained from the data, by means of a singular value analysis. Further details about the SIM and the several alternative implementations, the reader is referred to the literature ${ }^{9}$.

Identification of general industrial processes was considered $^{10}$, where the subspace identification method called N4SID was compared to the PEM (Prediction Error Method), with respect to computational complexity and prediction error value. From the outset, it must be stressed that the SIM and PEM are not competing methods, but complementary ones. For instance, initial order and system parameter estimates can be obtained by SIM, and then be given to the PEM as initial conditions. 
This work aims at showing the deduction of a model, tailored for control, for a tandem cold metal rolling of 5-stands, the dynamic simulation of this process and results with application of $\mathrm{SIMF}^{8}$, a new subspace identification method implementation that will be employed as basis for the research and development in new controllers. The results can enable advances in search of better quality for rolled products.

The main contributions of this paper are: a) a linear model for 5-tandem cold metal rolling mill in state-space representation is proposed, where the output vector contains not only the output thickness and interstand tension, but also the roll force; b) this model offers the possibility of performing disturbance analysis in process variables, such as mill thickness input, strip input tension on stand 1 and strip output tension on stand 5; c) interstand time delay is considered for a linear approximation, by using 4 first order lags in cascade and d) a new subspace identification method, called SIMF, was employed to obtain a state space model from input/output data and the result compared with the classical N4SID method, providing better performance, since the user has better control over the design parameters, which can hardly be automated when the system order is high, as in the present case.

With the above consideration in mind, the paper is organized as follows. In Section 2, the cold rolling process is mathematically described by classical equations and a state-space representation is derived. Then, in Section 3 some aspects of subspace identification are introduced. The results are shown in Section 4, where simulations for 3 operating points are performed and compared with the literature for validation. A $10^{\text {th }}$ order black-box model is identified via SIMF. Finally, the concluding remarks are presented in Section 5.

\section{Tandem Cold Rolling Process}

In the flat sheet production, the desired thickness is an important specification to achieve. Therefore the steel strip is passed through several stands in a tandem cold mill. Figure 1 illustrates this operation. The multiple stands cause considerable interaction of thickness and interstand tension. These variables interaction and the necessity to reach the dimensional specifications of steel strip give rise to a complex control problem. In order to control this process, output thickness and interstand tension are defined as controlled outputs. A state-space representation is presented here and can be used in the development of new control strategies.

\subsection{Process modeling}

In this process, the passage of the strip through the individual pairs of work rolls results in successive thickness reductions by compressive force applied to material in a small region, the roll bite shown in Figure 2. In rolling processes special attention is provided to strip deformation on roll bite. The mathematic model of the process, in this work, is composed by a set of algebraic equations greatly applied in industrial areas ${ }^{1}$.

The strip deformation occurs by the movement of the work rolls, caused by position and speed actuators that were treated by a first order dynamic with time constant adjusted with industrial practice and literature suggestions ${ }^{11}$.

The equations that compose this mathematical model are introduced later and Table 1 contains a symbol description used in this modeling. Below, the subscripts in and out mean the parameters values in input or output stand, respectively, $O$ indicates parameter in operating point and $i$ is associated to stand $i$.

The deformation modeling in roll bite is described by the specific roll force calculation. It is force by strip width in $\mathrm{kN} . \mathrm{mm}^{-1}$ and the forward slip calculation, the fractional increase in the speed of the strip exiting the roll bite area, dimensionless parameter.

The specific roll force is approximated by the following expression, where weighting coefficients ${ }^{1}$ are employed.

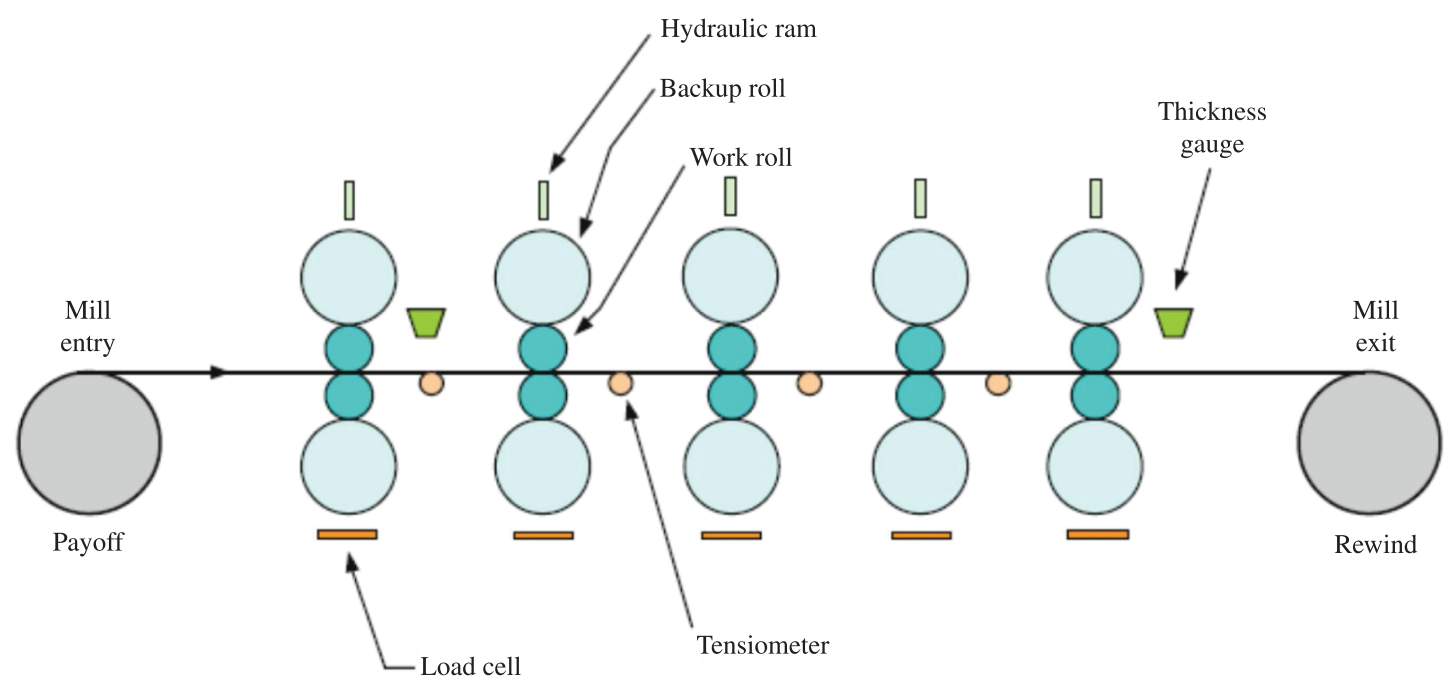

Figure 1. Typical 5-stand tandem cold mill ${ }^{11}$. 


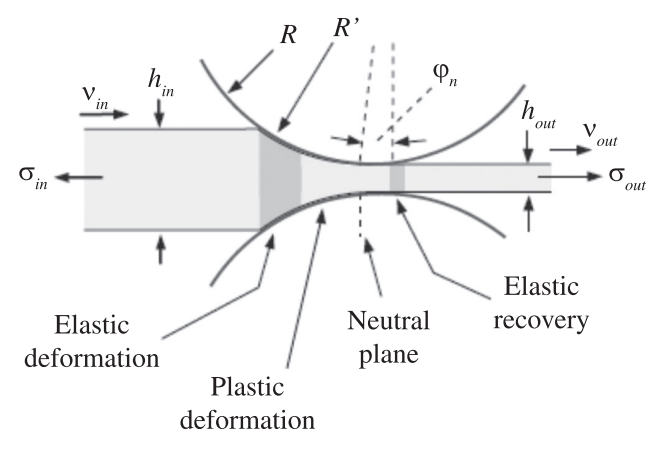

Figure 2. Schematic diagram for the material deformation in roll bite ${ }^{11}$.

Table 1. Symbol description.

\begin{tabular}{cc}
\hline Symbol & Description \\
\hline$P$ & Specific roll force \\
$\sigma$ & Compressive yield stress \\
$R$ & Tension stress \\
$\delta$ & Work roll radius \\
$h$ & Thickness reduction in stand \\
$\mu$ & Thickness \\
$H_{a}$ & Coefficient of friction \\
$E$ & Strip annealed thickness \\
$f$ & Young's module of strip \\
$V$ & Forward slip \\
$L_{0}$ & Strip speed \\
$S$ & Distance between adjacent \\
$F$ & mill stands \\
$W$ & Roll gap \\
$M_{m}$ & Total roll force \\
$\tau_{d}$ & Strip width \\
$V_{R}$ & Mill modulus \\
$U_{S}$ & Delay time \\
$U_{V}$ & Roll speed \\
$\tau_{S}$ & Roll gap control \\
$\tau_{V}$ & Speed control \\
$q, r$ & Roll gap time constant \\
& Speed time constant \\
\hline & Auxiliar variables \\
\hline & \\
\hline &
\end{tabular}

$$
\begin{aligned}
& P=\left(\left(0,2 k_{\text {in }}+0,8 k_{\text {out }}\right)-\left(\frac{2}{3} \sigma_{\text {in }}+\frac{1}{3} \sigma_{\text {out }}\right)\right) \\
& \sqrt{R^{\prime} \delta}\left(1+4\left(\sqrt{\frac{h_{\text {out }}}{h_{\text {in }}}} \exp \left(\frac{\mu \sqrt{R^{\prime} \delta}}{0,28 h_{\text {in }}+0,72 h_{\text {out }}}\right)-1\right)\right) \\
& k_{\text {in }(\text { out })}=0,819\left(0,002+r_{\text {in }(\text { out })}\right)^{0,27} \quad r_{\text {in }(\text { out })}=\frac{H_{a}-h_{\text {in }(\text { out })}}{H_{a}}
\end{aligned}
$$

The hypothesis of the circular arc contact and the flattening work roll allows the use of Hitchcock's formula ${ }^{12}$ for a deformed work roll radius, $R$ '.

The forward $\operatorname{sip} f$ is approximated by

$$
f=\left(\frac{\delta}{h_{\text {out }}}\right)\left(\begin{array}{l}
\frac{1}{2} \frac{h_{\text {out }}}{\left(0,28 h_{\text {in }}+0,72 h_{\text {out }}\right)} \sqrt{\frac{\delta}{R^{\prime}}} \\
-\frac{1}{4} \frac{h_{\text {out }} \delta}{\left(0,28 h_{\text {in }}+0,72 h_{\text {out }}\right) \mu R^{\prime}} \\
+\frac{1}{4} \frac{h_{\text {out }}\left(\frac{\sigma_{\text {out }}}{\mu R^{\prime}}-\frac{\sigma_{\text {in }}}{k_{\text {in }}}\right)}{\sqrt{\frac{\delta}{R^{\prime}}}}
\end{array}\right)^{2}
$$

The interstand tension is obtained by application of the Hookes's law to a length of strip between successive stands, namely

$$
\frac{\partial \sigma_{i, i+1}}{\partial t} \equiv \dot{\sigma}_{i, i+1}=\frac{E\left(V_{i n, i+1}-V_{o u t, i}\right)}{L_{0}}, \quad \sigma_{i, i+1}(0)=\sigma_{0, i, i+1}
$$

A linear approximation for the mill stretch of the rolling stand is used for estimates of output thickness,

$h_{\text {out }}=S+\frac{F}{M_{m}}$, where $\mathrm{F}=P W$

The interstand time delay is approximated by

$\tau_{d, i, i+1}=\frac{L_{0}}{V_{\text {out }, i}}$

By considering the time delay between adjacent mill stands, the input thickness is modeled by

$h_{\text {in }, i}(t)=h_{\text {out }, i-1}\left(t-\tau_{d i, i-1}\right)$

Taking into account the hypothesis of material continuity between adjacent stands and through the roll bite, (7) calculates all work roll peripheral speeds and strip input speeds on stands, once known the output strip speed of rolling mill.

$V_{\text {in }}=V_{\text {out }}\left(\frac{h_{\text {out }}}{h_{\text {in }}}\right)$ where $V_{\text {out }}=V_{R}(f+1)$

The dynamic comportment of roll gap and roll speed are approximated by first orders relations,

$\dot{S}_{i}=-\frac{S_{i}}{\tau_{S}}+\frac{U_{S i}}{\tau_{S}}$

$\dot{V}_{R i}=-\frac{V_{R i}}{\tau_{V}}+\frac{U_{V i}}{\tau_{V}}$

The set of equations described above are linearized and normalized. The linear approximation was performed with expansion on Taylor series. For normalization of any variable its value in the operating point was used, except in the case of the roll gap $S$, normalized by output thickness in operating point, $h_{\text {out } i 0}$. The following expression indicates a normalization procedure for a generic variable $\mathrm{x}$, that is a fractional variation of a referred variable $\mathrm{x}$ in relation to its value in operating point $\mathrm{x}_{0}$. 
$\overline{\Delta x}=\frac{x-x_{0}}{x_{0}}$

The calculation of coefficients in Equations 11 to 16 and 18 to 21 are detailed in another work ${ }^{13}$.

The roll force depends on the input and output thickness, input and output tension stress, friction, and material plastic characteristics. In this work, possibilities of variation in friction and material plastic characteristics will not be considered. The normalized and linearized variation of the specific roll force is,

$$
\overline{\Delta P}_{i}=e_{2 i} \overline{\Delta h}_{i n, i}+\left(e_{1 i}-1\right) \overline{\Delta S}_{i}+e_{3 i} \overline{\Delta \sigma}_{i n, i}+e_{4 i} \overline{\Delta \sigma}_{\text {out }, i}
$$

The output thickness depends on the position of roll positioner actuator and specific roll force. In these conditions, the normalized and linearized variation in output thickness is obtained by following expression,

$\overline{\Delta h}_{\text {out }, i}=e_{1 i} \overline{\Delta S}_{i}+e_{2 i} \overline{\Delta h}_{i n, i}+e_{3 i} \overline{\Delta \sigma}_{i n, i}+e_{4 i} \overline{\Delta \sigma}_{\text {out }, i}$

Similarly to roll force, the forward slip will be considered dependent only of the input and output thickness and input and output tension stress.

For interstand tension between stand 1 and 2, the linearized and normalized equation is

$$
\begin{aligned}
& \frac{d}{d t} \overline{\Delta \sigma}_{i n, 2}=M_{1} \overline{\Delta \sigma}_{i n, 2}+M_{2} \overline{\Delta \sigma}_{i n, 3}+M_{3} \overline{\Delta h}_{i n, 1}+M_{4} \overline{\Delta V}_{1} \\
& +M_{5} \overline{\Delta S}_{1}+M_{6} \overline{\Delta h}_{i n, 2}+M_{7} \overline{\Delta V}_{2}+M_{8} \overline{\Delta S}_{2}+M_{9} \overline{\Delta \sigma}_{i n, 1}
\end{aligned}
$$

For interstand tension between stand 2 and 3, the linearized and normalized equation is

$$
\begin{aligned}
& \frac{d}{d t} \overline{\Delta \sigma}_{i n, 3}=N_{1} \overline{\Delta \sigma}_{i n, 2}+N_{2} \overline{\Delta \sigma}_{i n, 3}+N_{3} \overline{\Delta h}_{i n, 2}+N_{4} \overline{\Delta V}_{2} \\
& +N_{5} \overline{\Delta S}_{2}+N_{6} \overline{\Delta h}_{i n 3}+N_{7} \overline{\Delta V}_{3}+N_{8} \overline{\Delta S}_{3}+N_{9} \overline{\Delta \sigma}_{i n, 4}
\end{aligned}
$$

For interstand tension between stand 3 and 4, the linearized and normalized equation is

$$
\begin{aligned}
& \frac{d}{d t} \overline{\Delta \sigma}_{i n, 4}=Q_{1} \overline{\Delta \sigma}_{i n, 3}+Q_{2} \overline{\Delta \sigma}_{i n, 4}+Q_{3} \overline{\Delta \sigma}_{i n, 5}+Q_{4} \overline{\Delta h}_{i n, 3} \\
& +Q_{5} \overline{\Delta h}_{i n, 4}+Q_{6} \overline{\Delta V}_{3}+Q_{7} \overline{\Delta V}_{4}+Q_{8} \overline{\Delta S}_{3}+Q_{9} \overline{\Delta S}_{4}
\end{aligned}
$$

For interstand tension between stand 4 and 5 , the linearized and normalized equation is $\frac{d}{d t} \overline{\Delta \sigma}_{i n 5}=R_{1} \overline{\Delta \sigma}_{i n 4}+R_{2} \overline{\Delta \sigma}_{i n 5}+R_{3} \overline{\Delta h}_{i n 4}+R_{4} \overline{\Delta h}_{i n 5}$
$+R_{5} \overline{\Delta V}_{4}+R_{6} \overline{\Delta V}_{5}+R_{7} \overline{\Delta S}_{4}+R_{8} \overline{\Delta S}_{5}+R_{9} \overline{\Delta \sigma}_{\text {out } 5}$

The normalized form for Equations 8 and 9, with $X=S$, for roll gap and $X=V$ for speed, is

$$
\frac{d \overline{\Delta X_{i}}}{d t}=\frac{\overline{\Delta U_{X_{i}}}}{\tau_{X}}-\frac{\overline{\Delta X_{i}}}{\tau_{X}} X_{i}(0)=0
$$

For simulating the delay time between two successive stands in linear form, 4 first order lags in cascade were used. The time constant used in each lag is equal to quarter part of nominal delay time between referred stands, i.e.,

$$
e^{-\tau_{d} s} \cong \frac{1}{\left(\frac{\tau_{d}}{4} s+1\right)^{4}}
$$

The input thickness in stand 2 is described by Equation 19, with auxiliary relations shown in Table 2.

$\frac{d}{d t} \overline{\Delta h}_{i n, 2}=\left(\overline{\Delta q}_{3}-\overline{\Delta h}_{i n, 2}\right)\left(\frac{4}{\tau_{d 1-2}}\right)$

The input thickness in stand 3 is described by Equation 20, with auxiliary relations shown in Table 2.

$\frac{d}{d t} \overline{\Delta h}_{i n, 3}=\left(\overline{\Delta r}_{3}-\overline{\Delta h}_{i n, 3}\right)\left(\frac{4}{\tau_{d 2-3}}\right)$

The Equations 21 and 22 are obtained of similar way ${ }^{13}$. The input thickness in stand 4 is described by,

$\frac{d}{d t} \overline{\Delta h}_{i n, 4}=\left(\overline{\Delta z}_{3}-\overline{\Delta h}_{i n, 4}\right)\left(\frac{4}{\tau_{d 3-4}}\right)$

The input thickness in stand 5 is described by,

$$
\frac{d}{d t} \overline{\Delta h}_{i n, 5}=\left(\overline{\Delta a}_{3}-\overline{\Delta h}_{i n, 5}\right)\left(\frac{4}{\tau_{d 4-5}}\right)
$$

\subsection{State-Space representation}

The obtained linear model was represented in state-space form. This representation followed the format given by Equation 23.

Table 2. Auxiliary relations for interstand delay time (first stands).

Auxiliary relations for stand delay 1-2

Auxiliary relations for stand delay 2-3

$$
\begin{gathered}
\frac{d}{d t} \overline{\Delta q}_{1}=\left(\overline{\Delta h}_{\text {out }, 1}-\overline{\Delta q}_{1}\right)\left(\frac{4}{\tau_{d 1-2}}\right) \\
\frac{d}{d t} \overline{\Delta q}_{2}=\left(\overline{\Delta q}_{1}-\overline{\Delta q}_{2}\right)\left(\frac{4}{\tau_{d 1-2}}\right) \\
\frac{d}{d t} \overline{\Delta q}_{3}=\left(\overline{\Delta q}_{2}-\overline{\Delta q}_{3}\right)\left(\frac{4}{\tau_{d 1-2}}\right)
\end{gathered}
$$

$$
\begin{gathered}
\frac{d}{d t} \overline{\Delta r}_{1}=\left(\overline{\Delta h}_{\text {out }, 2}-\overline{\Delta r}_{1}\right)\left(\frac{4}{\tau_{d 2-3}}\right) \\
\frac{d}{d t} \overline{\Delta r}_{2}=\left(\overline{\Delta r}_{1}-\overline{\Delta r}_{2}\right)\left(\frac{4}{\tau_{d 2-3}}\right) \\
\frac{d}{d t} \overline{\Delta r}_{3}=\left(\overline{\Delta r}_{2}-\overline{\Delta r}_{3}\right)\left(\frac{4}{\tau_{d 2-3}}\right)
\end{gathered}
$$


$\left\{\begin{array}{c}\dot{x}=A x+B u+D_{\text {in }} d \quad X(0)=0 \\ y=C x+D_{\text {out }} d\end{array}\right.$

The state vector $x$, the control input $u$, the disturbance vector $d$ and the output vector $y$ must be defined. Based on the dynamic linear equations showed in section 2.1, these vectors are

$x=\left[\begin{array}{lllllllll}\overline{\Delta \sigma}_{i n 2} \cdots \overline{\Delta \sigma}_{i n 5} & \overline{\Delta h}_{i n 2} \cdots \overline{\Delta h}_{i n 5} & \overline{\Delta q}_{1} & \overline{\Delta q}_{2} & \overline{\Delta q}_{3} & \overline{\Delta r}_{1} & \overline{\Delta r}_{2} & \overline{\Delta r}_{3}\end{array}\right.$

$\left.\begin{array}{llllllllll}\overline{\Delta z}_{1} & \overline{\Delta z}_{2} & \overline{\Delta z}_{3} & \overline{\Delta a}_{1} & \overline{\Delta a}_{2} & \overline{\Delta a}_{3} & \overline{\Delta V}_{1} \cdots \overline{\Delta V}_{5} & \overline{\Delta S}_{1} \cdots \overline{\Delta S}_{5}\end{array}\right]^{T}$

$u=\left[\overline{\Delta U}_{V_{1}} \cdots \overline{\Delta U}_{V_{5}} \overline{\Delta U}_{S_{1}} \cdots \overline{\Delta U}_{S_{5}}\right]^{T}$

$d=\left[\begin{array}{lll}\overline{\Delta h}_{i n, 1} & \overline{\Delta \sigma}_{i n, 1} & \overline{\Delta \sigma}_{\text {out }, 5}\end{array}\right]^{T}$

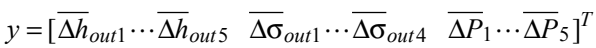

The system then have 30 states, 10 control inputs, 3 disturbance inputs and 14 outputs. Hence the system matrix, $A$, is $30 \times 30$, the input matrix, $B$, is $30 \times 10$, the output matrix, $C$, is $14 \times 30$, the input disturbance matrix, $D_{i n}$, is $30 \times 3$ and the output disturbance matrix, $D_{\text {out }}$ is $14 \times 3$.

\section{Subspace Identification}

System identification concerns structure and parameters determination from experimental data. As far as the structure is concerned, there are two possibilities: a) grey box: balance relations can be used to obtain the system mathematical model, regardless of the data, and b) black box: both structure and parameters are obtained from the experimental data.

When linear black box models are required, the Prediction Error Method (PEM) approaches has difficulty with the MIMO case, in the sense that inadequate selection of the model structure and parameterization can lead to numerical problems, due to poor identifiability ${ }^{14}$. Besides, PEM is based on recursive optimization, hence can converge to a local minimum.

An efficient alternative for black box MIMO systems identification are the SIM, which are based on the realization theory. This approach tackles adequately the 3 main difficulties arising in the identification of MIMO systems: a) there is no parameterization problem, for the model structure is also obtained from the experimental data; b) the solution is non-recursive, since it is based on the solution of 1 or more SVD (Singular Value Decomposition) problems, and c) there is no need for an initial state estimate. For some examples of SIM implementations, such as CVA $^{15}$ (Canonical Variate Analysis), N4SID ${ }^{16}$ (Numerical algorithm for Subspace State-Space System Identification) and MOESP $^{17}$ (Multivariable Output-Error State-Space) see Qin?

For performing system identification, consider the state space discrete time model with $n$ states, $m$ outputs and $l$ inputs, written in the innovation form, i.e.,

$\mathbf{x}(t+1)=\mathbf{A x}(t)+\mathbf{B u}(t)+\mathbf{K e}(t)$
$\mathbf{y}(t)=\mathbf{C x}(t)+\mathbf{D u}(t)+\mathbf{e}(t)$

which can also be rewritten in the predictor form as

$$
\mathbf{x}(t+1)=\overline{\mathbf{A}} \mathbf{x}(t)+\overline{\mathbf{B}} \mathbf{u}(t)+\mathbf{K y}(t)
$$

$\mathbf{y}(t)=\mathbf{C x}(t)+\mathbf{D u}(t)+\mathbf{e}(t)$

For closed loop identification, representation (30)-(31) is convenient, since $\overline{\mathbf{A}}$ is stable, even if the original dynamic matrix $A$ in (28) is unstable. For further details, see Qin ${ }^{9}$ (2006).

The identification of (30)-(31) via a subspace method, in open or closed loop, can be carried out as in reference 8 and amounts to the estimation of the dimension of the state space, namely, the value of $n$, and all the corresponding 5 matrices $\{A, B, K, C, D\}$ in (28)-(29). The matrix $K$ in (30) corresponds to the steady state Kalman Filter gain, hence the identification method is robust to noise.

\section{Results and Discussion}

The operating point definition is necessary for the determination of a linearized model. For the validation of this model, three typical operating conditions of 5-stand tandem mill were adopted ${ }^{1,2,11}$. Comparisons of the results obtained by these authors with results of this work are presented. For each simulated case, a disturbance in input thickness of stand 1 was applied and their effects evaluated in the output thicknesses, roll forces and interstand tensions.

\subsection{Operating conditions and characteristics of the rolling mill/strip}

The operating conditions of rolling mill are defined by choice of the operating point. In Table $3 \mathrm{a}$ are defined the three cases considered and Table $3 \mathrm{~b}$ also shows the characteristics of the mill and strip used in the simulation.

\subsection{Validation of the Linear Model}

The variations in output thicknesses, roll forces and interstand tensions were registered after the application of a step with amplitude 2 in input thickness of stand 1, which means to apply a variation of $+2 \%$ in its parameter. The results were obtained for each operating point and Table 4 compares the results obtained in this work (Model), with the of Bryant, Geddes and Pittner ${ }^{11}$. The values in Table 4 are the average of the results obtained in the 3 operating points.

In general the results were satisfactory, as shown in Table 4. For output thickness, in Bryant ${ }^{1}$, a reference in mill control, the results obtained by the linear model shows a good consistency relative to the initial stands. With relation to roll force, there is consistency in the stand 1 and the results of linear model are better in comparison with the others authors to stand 5. Some differences were detected in output tension stress, fact occurred in all works.

Several facts can be singled out as responsible for the differences observed: (a) the utilization of models with algebraic nature and empirical calculation of roll force and forward slip ${ }^{1}$, where simplicity is wished. The Bryant's model is widely used in control systems of industrial mills. There are models with better precision for this calculates ${ }^{18}$. 
Some effects can be added to the model for improving the results, such as the material elasticity in roll bite and strain rate; (b) the system linearization: The linear model offers a good response when input variations leave the system varying around the $\pm 5 \%$ of the operating point, which is case in this work; (c) the friction modeling: In Pittner's model ${ }^{8}$ the friction is dependent on draft-diameter rate in work roll, speed roll and frictional characteristics. In this work the friction is constant. Finally, (d) the time delay interstand was considered constant and non-dependent of output speed of the stand.

\subsection{Open loop identification}

Since the model has variables with different time and amplitude scales, and also large order, the data is bound to be badly conditioned. This can be seen in 2 ways: a) the singular value analysis indicated a model with lower order then the true one, and b) the prediction capability is sensitive to the SVD threshold employed for solving the ensuing LS problems.

In Figure 3 it is shown the performance for the output $\mathrm{Y}(14)$, roll force in stand 5, where SIMF is the subspace

Table 3. Operating points and characteristics of the rolling mill and strip.

\begin{tabular}{|c|c|c|c|}
\hline \multirow[t]{2}{*}{ Parameter } & \multicolumn{3}{|c|}{ Operating point $n .^{\circ}$} \\
\hline & 1 & 2 & 3 \\
\hline$h_{i n l}(\mathrm{~mm})$ & 3.56 & 2.36 & 1.78 \\
\hline$h_{\text {out } 1}(\mathrm{~mm})$ & 2.95 & 2.01 & 1.22 \\
\hline$h_{\text {out } 2}(\mathrm{~mm})$ & 2.44 & 1.52 & 0.79 \\
\hline$h_{\text {out } 3}(\mathrm{~mm})$ & 2.01 & 1.22 & 0.56 \\
\hline$h_{\text {out } 4}(\mathrm{~mm})$ & 1.68 & 0.97 & 0.38 \\
\hline$h_{\text {out } 5}(\mathrm{~mm})$ & 1.58 & 0.91 & 0.36 \\
\hline$\sigma_{i n l}\left(\mathrm{kN} \cdot \mathrm{mm}^{-2}\right)$ & 0.0 & 0.0 & 0.0 \\
\hline$\sigma_{i n 2}\left(\mathrm{kN} \cdot \mathrm{mm}^{-2}\right)$ & 0.080 & 0.103 & 0.111 \\
\hline$\sigma_{i n 3}\left(\mathrm{kN} \cdot \mathrm{mm}^{-2}\right)$ & 0.078 & 0.126 & 0.132 \\
\hline$\sigma_{i n 4}\left(\mathrm{kN} \cdot \mathrm{mm}^{-2}\right)$ & 0.057 & 0.096 & 0.132 \\
\hline$\sigma_{i n 5}\left(\mathrm{kN} . \mathrm{mm}^{-2}\right)$ & 0.055 & 0.060 & 0.085 \\
\hline$\sigma_{\text {out } 5}\left(\mathrm{kN} \cdot \mathrm{mm}^{-2}\right)$ & 0.028 & 0.028 & 0.028 \\
\hline
\end{tabular}

(a)

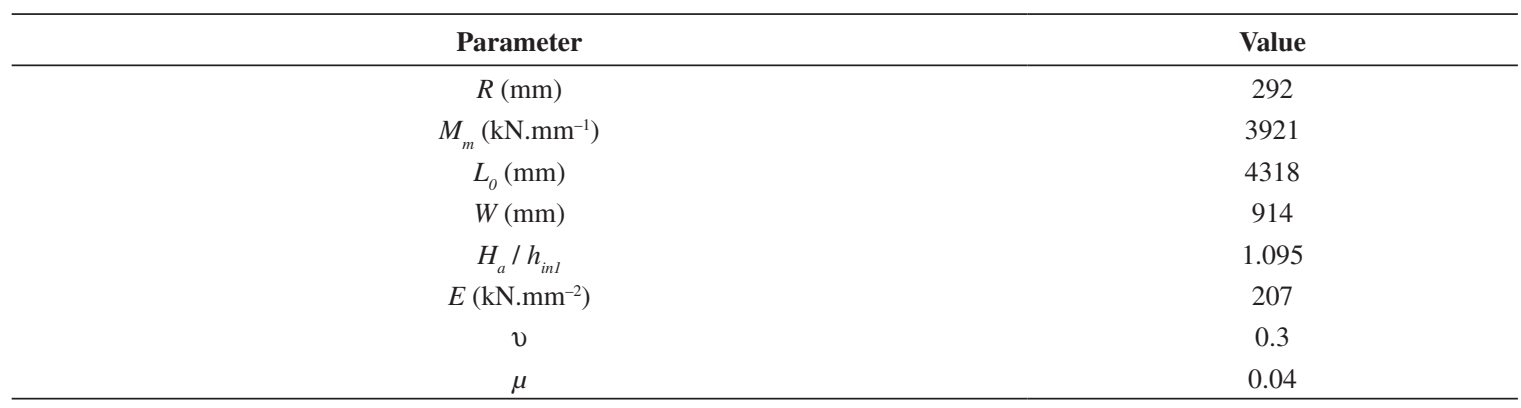

(b)

Table 4. $+2 \%$ Step change in stand 1 input thickness.

\begin{tabular}{|c|c|c|c|c|c|c|}
\hline \multirow[t]{2}{*}{ Variable } & \multirow[t]{2}{*}{ Source } & \multicolumn{5}{|c|}{ Fractional change in variable \% (Steady-State) } \\
\hline & & Stand 1 & Stand 2 & Stand 3 & Stand 4 & Stand 5 \\
\hline \multirow{4}{*}{ Output thickness } & Bryant & 1.8 & 1.8 & 1.8 & 1.8 & 1.7 \\
\hline & Geddes & 2.32 & 2.13 & 1.90 & 2.14 & 2.21 \\
\hline & Pittner/Simaan & 2.40 & 2.38 & 2.39 & 2.31 & 2.42 \\
\hline & Model & 1.702 & 1.47 & 1.448 & 1.132 & 1.122 \\
\hline \multirow{4}{*}{ Roll force } & Bryant & 2.0 & 1.3 & 0.9 & 0.5 & 0.8 \\
\hline & Geddes & 3.23 & 2.27 & 1.30 & 1.23 & 1.68 \\
\hline & Pittner/Simaan & 2.17 & 1.67 & 1.35 & 1.09 & 1.57 \\
\hline & Model & 1.702 & 1.47 & 1.448 & 1.132 & 1.122 \\
\hline \multirow{4}{*}{ Output tension stress } & Bryant & -trace & - trace & + trace & -trace & - \\
\hline & Geddes & + trace & 1.7 & 4.6 & -2.4 & - \\
\hline & Pittner/Simaan & 1.2 & 0.7 & 0.4 & 8.8 & - \\
\hline & Model & -5.15 & -5.24 & -4.59 & -5.14 & - \\
\hline
\end{tabular}




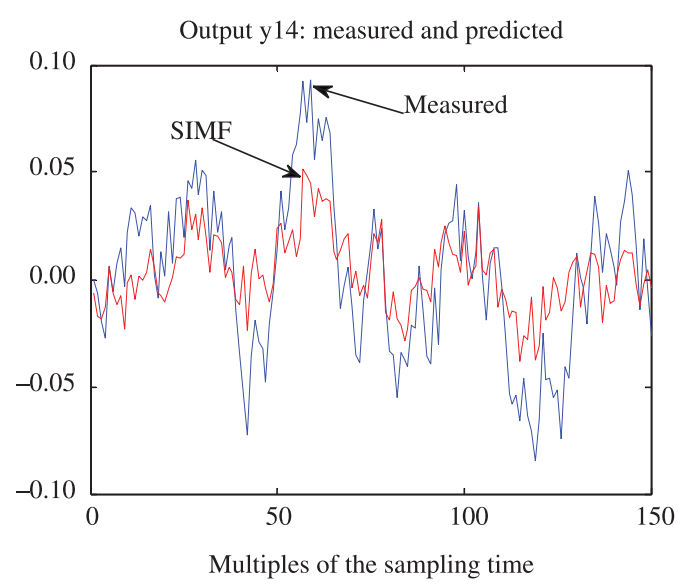

(a)

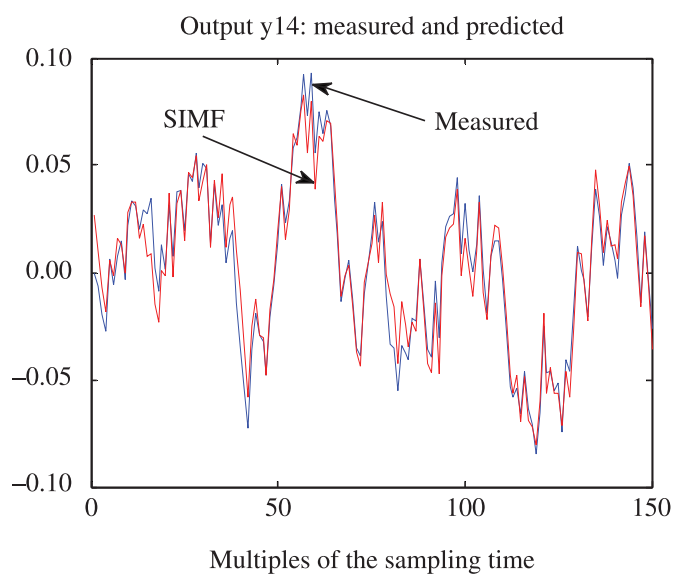

(b)

Figure 3. Output $Y(14)$, roll force in stand 5: measured and predicted, for tol=1e-9 (a) and 1e-6 (b), for 10 states.

identification method employed in this work, by considering a black-box model with 10 states.

From Appendix 1it is concluded that the SVD threshold selection is critical for performance.

This occurs to all the outputs, as can be seen from Appendix 1, where the Theil coefficients are shown.

The ideal value for $\mathrm{UC}$ is 1 , which means zero prediction error, and from the first table in Appendix 1, mainly for output 9 , the result is far from the ideal one, when the tolerance is too small. In the second table, for a larger threshold, the results are adequate.

The bad data conditioning makes the automation of subspace methods a complicated task, as can be seen in Figure 4, where the SIMF is compared with the method N4SID-Matlab: even with the selection of CVA method and focus on prediction, good result is not obtained.

The dynamic matrices obtained by SIMF are shown in Appendix 2.

We now consider the case with 30 states. The result for output $Y(14)$ is shown in Figure 5.

Compare the predicted value with those in Figure 3. The results for the correct order show very small prediction

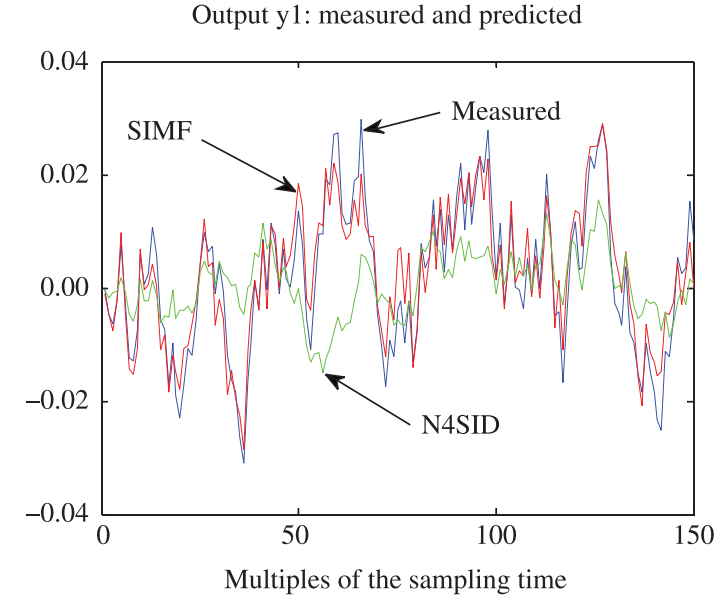

Figure 4. Performance comparison: SIMF and N4SID-Matlab.

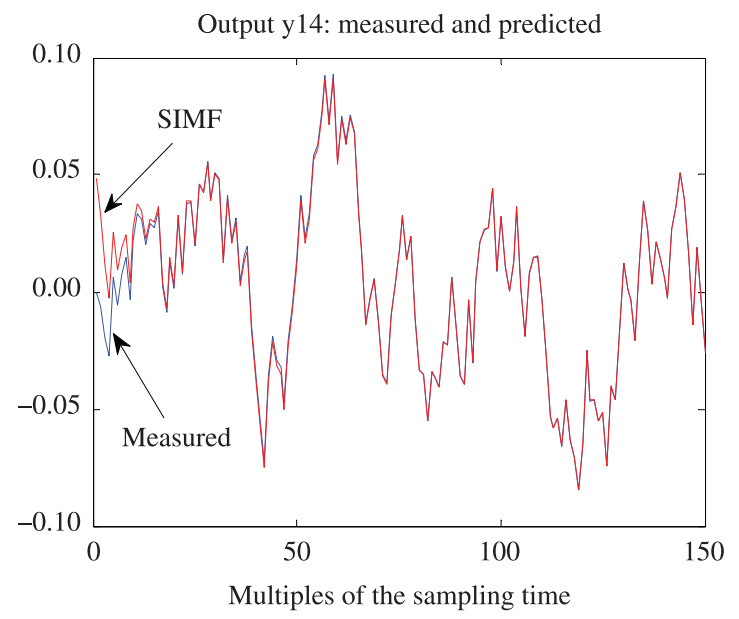

Figure 5. Output $\mathrm{Y}(14)$ : measured and predicted values.

error, as expected, since the output data was generated with low noise content.

\section{Conclusions}

The model deduced here is tailored for control, useful for studies and researches on new control strategies applied to tandem mill. The obtained results are coherent and robust to design parameters. The variations due to the input disturbances have small amplitude and the linearized model seemed adequate.

The state-space modeling offered the correct treatment for a multivariable system, favoring the access to internal variables, to state variables, and not only to output variables.

The SIMF showed superior performance when compared with N4SID-MatLab, even with data bad-conditioned, since the user has control on some key design parameters, which cannot be easily automated, mainly when large order MIMO systems are considered.

This work has then proposed procedures for modeling and identification of rolling mills, which can enable more accurate simulation and the development of better control strategies. Experimental results, for both identification and control, will be presented elsewhere. 


\section{References}

1. Bryant CF. Automation of Tandem Mills. London: British Iron Steel Institute; 1973.

2. Geddes EJM and Postlethwaite I. Improvements in Product Quality in Tandem Cold Rolling Using Robust Multivariable Control. IEEE Transactions on Control Systems Technology. 1998; 6(2):257-269. http://dx.doi. org/10.1109/87.664192

3. Hoshino I, Maekawa Y, Fujimoto T, Kimura H and Kimura H. Observer-based multivariable control of the aluminum cold tandem mill. Automatica. 1988; 24(6):741-754. http://dx.doi. org/10.1016/0005-1098(88)90050-7

4. Asano K and Morari M. Inteaction measure of tension-thickness control in tandem cold rolling. Control Engineering Practice. 1998; 6:1021-1027. http://dx.doi.org/10.1016/ S0967-0661(98)00101-4

5. Lee WH and Lee SR. Computer Simulation of Dynamic Characteristics of Tandem Cold Rolling Process. KSME International Journal. 1999; 13(8):616-624.

6. Pittner J, Samaras NS and Simaan MA. A Simple Rolling Mill Model with Linear Quadratic Optimal Controller. IEEE, IAS; 2002. p. 142-149.

7. Kim SS, Kim J-S, Yang S-Y, Lee B-R, Ahn K-K. Hœ Control System for Tandem Cold Mills with Roll Eccentricity. KSME International Journal. 2004; 18(1):45-54.

8. Hemerly EM. Breckenfeld, R. P. Camolesi, V. J. Subspace Identification for Open and Closed Loop Petrochemical Plants. In: Proceedings of 21st Brazilian Congress of Mechanical Engineering - ABCM; 2011; Natal. Natal; 2011.

9. Qin SJ. An overview of subspace identification. Computers \& Chemical Engineering. 2006; 30:1502-1513. http://dx.doi. org/10.1016/j.compchemeng.2006.05.045

10. Favoreel W, De Moor B and Van Overschee P. Subspace state space system identification for industrial processes. Journal of
Process Control. 2000; 10:149-155. http://dx.doi.org/10.1016/ S0959-1524(99)00030-X

11. Pittner J and Simaan MA. Tandem Cold Metal Rolling Mill Control - Using Practical Advanced Methods. London: Springer-Verlag; 2011. http://dx.doi. org/10.1007/978-0-85729-067-0

12. Roberts WL. Mathematical models related to rolling force. In: Roberts WL. Cold rolling of steel. New York: Marcel Dekker; 1978.

13. Alves PG, Moreira LP and Castro JA. Dynamic Simulator for Control of Tandem Cold Metal Rolling. In: Proceedings of $21^{s}$ Brazilian Congress of Mechanical Engineering-ABCM; 2011; Natal. Natal; 2011.

14. Katayama T. Subspace Methods for System Identification. London: Springer-Verlag; 2005.

15. Larimore WE. Canonical variate analysis in identification, filtering and adaptive control. In: Procedings of the 29-th Conference on Decision and Control; 1990; Hawai. Hawai; 1990. p. 596-604.

16. Van Overschee P and De Moor B. N4SID: Subspace algorithms for identification of combined deterministic-stochastic systems. Automatica. 1994; 30:75-93. http://dx.doi. org/10.1016/0005-1098(94)90230-5

17. Verhaegen $M$ and Dewilde P. Subspace model identification, part i: The output-error state-space model identification class of algorithms. International Journal of Control. 1992; 56:1187-1210. http://dx.doi. org/10.1080/00207179208934363

18. Alves PG and Hemerly EM. Modeling and numerical simulation of the deformation for calculations of set-up parameters in processes of cold rolling. In: Procedings of the 44th Rolling Seminar - Processes, Rolled and Coated products - ABM; 2007; São Paulo. São Paulo; 2007.

Appendix 1. Theil coefficients for tol=1e-9 (a) and 1e-6 (b).

\begin{tabular}{|c|c|c|c|c|}
\hline & $\mathrm{U}$ & UB & UV & UC \\
\hline Output 1: & 0.567580 & 0.007105 & 0.317475 & 0.675421 \\
\hline Output 2: & 0.565649 & 0.000128 & 0.187938 & 0.811933 \\
\hline Output 3: & 0.627186 & 0.023985 & 0.201655 & 0.774360 \\
\hline Output 4: & 0.574484 & 0.006695 & 0.187044 & 0.806260 \\
\hline Output 5: & 0.798843 & 0.019087 & 0.208902 & 0.772011 \\
\hline Output 6: & 0.556228 & 0.002733 & 0.261293 & 0.735975 \\
\hline Output 7: & 0.327011 & 0.001680 & 0.097975 & 0.900345 \\
\hline Output 8: & 0.472826 & 0.010553 & 0.134884 & 0.854563 \\
\hline Output 9: & 0.807412 & 0.001816 & 0.636091 & 0.362093 \\
\hline Output 10: & 0.536586 & 0.005577 & 0.269294 & 0.725129 \\
\hline Output 11: & 0.571612 & 0.001000 & 0.305553 & 0.693448 \\
\hline Output 12: & 0.348290 & 0.005680 & 0.090454 & 0.903866 \\
\hline Output 13: & 0.459018 & 0.001470 & 0.091679 & 0.906850 \\
\hline Output 14: & 0.751597 & 0.001903 & 0.669019 & 0.329079 \\
\hline
\end{tabular}

(a)

\begin{tabular}{|c|c|c|c|c|}
\hline & U & UB & UV & $U C$ \\
\hline Output 1: & 0.430993 & 0.000572 & 0.088007 & 0.911421 \\
\hline Output 2: & 0.413674 & 0.012932 & 0.035204 & 0.951863 \\
\hline Output 3: & 0.535990 & 0.015806 & 0.062827 & 0.921367 \\
\hline Output 4: & 0.561794 & 0.012110 & 0.099453 & 0.888438 \\
\hline Output 5: & 0.551276 & 0.019112 & 0.100683 & 0.880205 \\
\hline Output 6: & 0.276944 & 0.003669 & 0.004303 & 0.992028 \\
\hline Output 7: & 0.273381 & 0.006997 & 0.002109 & 0.990894 \\
\hline Output 8: & 0.274753 & 0.001181 & 0.000073 & 0.998746 \\
\hline Output 9: & 0.248868 & 0.000618 & 0.002862 & 0.996520 \\
\hline Output 10: & 0.406679 & 0.000207 & 0.065911 & 0.933881 \\
\hline Output 11: & 0.329182 & 0.004496 & 0.008018 & 0.987487 \\
\hline Output 12: & 0.273092 & 0.002611 & 0.000640 & 0.996749 \\
\hline Output 13: & 0.317150 & 0.001510 & 0.000633 & 0.997857 \\
\hline Output 14: & 0.307267 & 0.000292 & 0.001970 & 0.997738 \\
\hline
\end{tabular}

(b) 
Appendix 2. Identified system matrices.

$\mathrm{A}=$

$\begin{array}{rrrrrrrrrr}0.7730 & 0.2783 & 0.0282 & -0.1456 & -0.0053 & -0.1389 & -0.1414 & -0.0279 & 0.1422 & -0.0735 \\ 0.2563 & 0.2699 & -0.2303 & 0.0168 & -0.1958 & 0.1923 & -0.0407 & -0.1531 & -0.3017 & 0.1775 \\ 0.0019 & -0.0360 & 0.7033 & -0.1208 & 0.1569 & -0.0102 & 0.1096 & -0.0125 & -0.0203 & 0.1281 \\ -0.0066 & -0.0561 & -0.0319 & 0.7530 & -0.0318 & 0.1492 & -0.1881 & -0.1354 & 0.0565 & -0.0187 \\ -0.0480 & -0.1180 & -0.0213 & -0.0637 & 0.7215 & 0.0135 & -0.1846 & -0.0768 & -0.0481 & -0.0105 \\ -0.0212 & 0.0998 & 0.1033 & 0.1081 & -0.0123 & 0.6523 & 0.1224 & 0.1418 & -0.0078 & 0.0034 \\ 0.0036 & 0.0103 & 0.0083 & -0.0584 & 0.0020 & 0.1164 & 0.7455 & -0.0674 & 0.0223 & -0.0763 \\ -0.0783 & 0.0955 & 0.0032 & -0.2326 & 0.0831 & 0.3975 & -0.3499 & 0.5402 & 0.1911 & -0.1892 \\ 0.0130 & -0.0016 & 0.0487 & 0.1821 & -0.0900 & -0.2038 & 0.1073 & 0.1413 & 0.8050 & 0.0726 \\ -0.0035 & 0.0313 & 0.0251 & -0.0522 & 0.0452 & 0.1593 & -0.1323 & -0.1153 & 0.1018 & 0.8515\end{array}$

$\mathrm{B}=$

$\begin{array}{rrrrrrrrrr}-3.8383 & 2.3731 & -1.1001 & 7.2072 & -3.7129 & 0.5050 & 2.2059 & 0.4906 & 0.5930 & -1.2175 \\ 4.4073 & -5.8420 & 4.1902 & -7.0818 & 5.1284 & -0.6186 & -4.3770 & 3.1302 & -3.6631 & -0.0702 \\ -5.4548 & 11.4234 & -9.3562 & 2.7594 & 1.1733 & 0.8048 & 0.9276 & 2.5921 & -3.5118 & 1.5182 \\ -3.5584 & -0.9888 & 7.5311 & -3.4156 & 0.0809 & 2.7017 & 2.3230 & 3.2061 & 0.2691 & 1.0547 \\ 0.6295 & -1.7874 & 3.0458 & 3.5189 & -4.7136 & 3.3900 & -2.7897 & 0.4308 & 0.1996 & -2.2752 \\ -1.2628 & 3.4944 & -2.0955 & 5.1996 & -5.3869 & -0.0071 & 1.7499 & -2.8746 & -2.4579 & -4.4674 \\ 2.3655 & -4.6963 & -0.0126 & 5.1324 & -3.2961 & -0.0172 & -0.6176 & 3.5581 & 3.2820 & -1.7671 \\ 1.4910 & -4.5668 & 1.8657 & -0.8076 & 0.4768 & -1.3281 & -0.1135 & 3.6240 & 1.0167 & 2.0741 \\ -4.5495 & 1.5083 & 9.0428 & -5.6531 & -0.0415 & -0.0645 & -2.9071 & -0.3951 & -2.5686 & -1.8867 \\ -10.3212 & 10.2513 & -0.1450 & -4.2444 & 3.6312 & -1.2112 & 0.0547 & 0.2708 & 3.0145 & -0.5151\end{array}$

$\mathrm{C}=$

$\begin{array}{rrrrrrrrrr}-0.0008 & -0.0024 & 0.0020 & 0.0050 & 0.0092 & -0.0010 & 0.0009 & -0.0036 & -0.0002 & -0.0032 \\ -0.0037 & -0.0017 & -0.0014 & 0.0035 & -0.0020 & 0.0036 & -0.0027 & -0.0005 & -0.0050 & -0.0002 \\ -0.0034 & -0.0003 & 0.0039 & 0.0017 & -0.0002 & -0.0007 & 0.0011 & 0.0023 & 0.0018 & -0.0006 \\ -0.0018 & -0.0015 & -0.0016 & -0.0001 & 0.0016 & -0.0001 & 0.0016 & -0.0003 & -0.0007 & 0.0031 \\ -0.0008 & -0.0013 & 0.0008 & 0.0006 & -0.0004 & -0.0019 & -0.0021 & 0.0013 & -0.0001 & -0.0007 \\ 0.0143 & 0.0231 & -0.0167 & 0.0960 & -0.0758 & 0.0516 & -0.0236 & -0.0349 & -0.0572 & 0.0235 \\ 0.0111 & 0.0013 & 0.0393 & 0.0906 & -0.1098 & -0.0136 & 0.1359 & -0.0130 & 0.0966 & -0.0595 \\ 0.0008 & -0.0198 & -0.0125 & -0.0140 & -0.0264 & -0.0914 & 0.1537 & -0.1337 & -0.0597 & 0.0429 \\ 0.0136 & -0.0308 & -0.0113 & 0.0335 & -0.0662 & -0.2301 & -0.0914 & -0.0968 & 0.0098 & -0.0248 \\ 0.0010 & 0.0038 & -0.0032 & -0.0130 & -0.0146 & -0.0000 & -0.0009 & 0.0081 & 0.0025 & 0.0051 \\ -0.0024 & -0.0031 & 0.0039 & -0.0199 & 0.0165 & -0.0106 & 0.0013 & 0.0065 & 0.0119 & 0.0003 \\ -0.0015 & -0.0002 & -0.0105 & -0.0105 & 0.0139 & 0.0060 & -0.0237 & 0.0019 & -0.0137 & 0.0072 \\ -0.0009 & 0.0038 & 0.0079 & 0.0024 & -0.0001 & 0.0159 & -0.0141 & 0.0169 & 0.0085 & -0.0095 \\ -0.0029 & 0.0054 & -0.0028 & -0.0037 & 0.0079 & 0.0247 & 0.0159 & 0.0012 & 0.0006 & 0.0095\end{array}$

